\author{
Presented at: High Aspects Ration Micro Systems Technology (HARMST) ‘97 \\ Madison, WI \\ June 20-21, 1997
}

BNL- 64629

Conf- $9706176-$

\title{
A Hard X-ray Prototype Production Exposure Station
}

E. D. Johnson and J. C. Milne

Brookhaven National Laboratory

Upton, NY 11973-5000

July 1997

DISCLAIMER

This report was prepared as an account of work sponsored by an agency of the United States Government. Neither the United States Government nor any agency thereof, nor any of their employees, makes any warranty, express or implied, or assumes any legal liability or responsibility for the accuracy, completeness, or usefulness of any information, apparatus, product, or process disclosed, or represents that its use would not infringe privately owned rights. Reference herein to any specific commercial product, process, or service by trade name, trademark, manufacturer, or otherwise does not necessarily constitute or imply its endorsement, recommendation, or favoring by the United States Government or any agency thereof. The views and opinions of authors expressed herein do not necessarily state or reflect those of the United States Government or any agency thereof.

National Synchrotron Light Source Brookhaven National Laboratory Upton, NY 11973

Work performed under the auspices of the U.S. Department of Energy, under contract DE-AC02-76CH00016. 


\section{DISCLAMIER}

Portions of this document may be illegible in electronic image products. Images are produced from the best available original docoment. 


\title{
A Hard X-ray Prototype Production Exposure Station at NSLS
}

\author{
Erik D. Johnson and J. Christopher Milne \\ Brookhaven National Laboratory, Upton, New York, 11973
}

Exposures conducted at the NSLS R\&D beamline (X-27B) for High Aspect Ratio Precision Manufacture have proven sufficiently successful that we are constructing a dedicated hard $\mathrm{x}$-ray exposure beamline. The new beamline (X-14B) provides an exposure field $\sim 120 \mathrm{~mm}$ wide, three times larger than that of $\mathrm{X}-27 \mathrm{~B}$. The scanner is based on the hydraulic system from the X-27B program. It is optimized for planar exposures and takes advantage of the full $525 \mathrm{~mm}$ stroke available. Exposures of multiple substrates and masks will be possible, with the fixturing supporting mounting of substrate holders from other groups (ALS, APS, CAMD, and UW). The function of this beamline is to establish a hard $\mathrm{x}$-ray exposure station where manufacturing scale protocols can be developed and ultimately exploited for production runs.

\section{Introduction}

The National Synchrotron Light Source (NSLS) has initiated a deep x-ray lithography (DXRL) program utilizing the unique properties of its X-ray storage ring. The research beamline X-27B has been the primary location for DXRL at the NSLS and has demonstrated the advantages of the relatively high photon energy and high flux density available for exposing resist (polymethylmethacrylate (PMMA)) in thickness' of $10 \mathrm{~mm}$ or more (Siddons et al (1994) and Johnson et al (1996)).

$\mathrm{X}-27 \mathrm{~B}$ has served us well as a research and development beamline, but due to the limited width of its available radiation fan, it is not ideally suited for the demands of DXRL production work. X27-B has a $6 \mathrm{~h}$-mrad radiation fan and is located $\sim 7.5 \mathrm{~m}$ from the source, producing an exposure region of about $45 \mathrm{~mm}$. To maintain flexibility for exposure tool development, the present beamline scanner has a large working platform which also effectively limits the maximum exposure scan distance to about $120 \mathrm{~mm}$. Although the beamline is not optimized for production type work, it has developed a large user base from a variety of government institutions and universities, motivating us to initiate construction of a prototype DXRL production exposure station. 


\subsection{Exposure Station Beamline Design}

\section{$2.1 \quad \mathrm{X}-14 \mathrm{~B}$ Characteristics}

To make production costs as low as feasible, the exposure station must possess a wide radiation fan and also high photon flux in the preferred energy region $(\sim 15 \mathrm{keV})$. After surveying the NSLS experimental floor for an availlable x-ray port, it was determined that the "B" branch on X-14 would fulfill both of these requirements. It had the further advantage that a mask and safety shutter was already installed in the front end to extract the radiation. The beamline would however have to coexist with an operational research beamline already in place, which severely restricts the available space on the experimental floor. The X-14B front end has a $18 \mathrm{~h}-\mathrm{mrad}$ beam defining aperture and has a source to exposure distance of $6.5 \mathrm{~m}$, providing a radiation fan of $\sim 120 \mathrm{~mm}$. At 6.5 $\mathrm{m}$ from the source, X-14B will supply $2.4 \times 10^{14}$ photons $/ \mathrm{s} / \mathrm{mm}^{2}$ (with an energy greater than $15 \mathrm{keV}$ ) at $438 \mathrm{~mA}$ and $2.584 \mathrm{GeV}$, and $2.6 \times 10^{14}$ photons $/ \mathrm{s} / \mathrm{mm}^{2}$ at $250 \mathrm{~mA}$ and $2.800 \mathrm{GeV}$.

\subsection{X-14B Design Considerations}

With the decision to construct a dedicated DXRL production exposure station, we drew upon our experience from X-27B and also solicited input from the DXRL user community for desirable features during a Microfabrication Workshop held during the 1996 NSLS Annual Users meeting (Siddons and Johnson (1996)). Several design considerations emerged as being critical for a successful exposure station.

Clearly, one must provide photons as economically as possible. This translates into providing a high flux density and also a wide radiation fan. In addition, the beamline must have a large exposure throughput. From our experience at X-27B the best way to achieve this end is to expose multiple resists in a single pass, since a significant amount of scanning time is spent decelerating and then accelerating the scan stage after each pass through the x-ray beam. In order to scan multiple resists, the scan stage must be able to provide a long stroke. The scan stage which we have designed for X-14B is driven by a hydraulic cylinder and provides $525 \mathrm{~mm}$ of scanning distance with computer controlled velocities (Milne and Johnson (1997)). 
It is also widely accepted that the exposure environment should have temperature and humidity control to stabilize the resist. For the X-14B station, both can be set to user specifications by the station control system. Based on a Labview platform with a graphical user interface (GUI) developed at BNL, the system has been met with great enthusiasm by our users. The control panel variables are based on high levelexposure parameters instead of detailed scanner settings, which immediately couches the exposure in terms which are relevant for subsequent processing. Using this interface will also reduce training time for those users already familiar with the X-27B GUI.

\subsection{X-14B Status and Commissioning}

As of June 1997, the X-14B beamline construction has been completed. The beamline has two $250 \mu \mathrm{m}$ thick Be windows which provide vacuum integrity. In addition to the physical beamline (which ends at the downstream Be window), $\mathrm{X}-14 \mathrm{~B}$ consists of two radiation enclosures. These enclosures have been designed and will be installed by December 1997. The upstream radiation enclosure will house computer controlled beam filters so the user will be able to tailor the $\mathrm{x}$-ray spectrum to suit their specific application. The downstream radiation enclosure will house the scanning apparatus and resist/mask fixturing. The beamline control system has already been assembled and tested.

First light was taken from the beamline (sans the radiation enclosures and scanning system) on February 19, 1997 during a controlled access for studies at low current. The full $\sim 120 \mathrm{~mm}$ radiation fan was present and centered in the beam pipe. The pacing item for completion of the installation will be an upgrade to the beamline interlocks which requires a long maintenance shutdown. The next scheduled slot of suitable duration is scheduled for December 1997; beamline commissioning should commence in January 1998.

\subsection{X-14B User Access}

After initial commissioning, non-proprietary access will be by proposal through the NSLS user administration office. Beamtime awarded through this process is available at no cost to the user. For proprietary and production runs, a proposal must be provided so 
a safety evaluation can be made, with beamtime allocated as available and charged at a rate commensurate with full cost recovery. Our long term goal would be to have available an operational mode for qualified users to send material to be exposed by beamline personnel who would document the actual exposure conditions and return the exposed material to the user. The cost for this type of work will be based on our experience in the initial stages of operating this new bearnline, and of course predicated on a need for such a service.

\subsection{Summary}

The NSLS has initiated a new program to provide a hard x-ray exposure station for manufacturing development. The beamline should be available for outside users in early 1998 and, to the best of our knowledge, represents the first such beamline intended to develop a base resource for manufacturing of HARMST devices.

\subsection{References}

Siddons, D.P; Johnson E.D.; Gückel H. (1994) Precision Machining with Hard X-rays. Synchrotron Radiation News; Vol. 7, No. 2:16-18

Johnson E.D.; Milne J.C.; Siddons, D.P; Gückel H.; Klein J.L.; (1996) Precision Machining with Hard X-rays: Experiments at the NSLS. Synchrotron Radiation News; Vol. 9, No. 4:10-13

Siddons, D.P; Johnson E.D. (1996) Hard X-ray Precision Fabrication Workshop. Synchrotron Radiation News; Vol. 9, No. 5:6-7

Milne J.C.; Johnson E.D. (1997) High Speed Hydraulic Scanner for Deep X-ray Lithography. These proceedings.

The NSLS is supported by the United States Department of Energy under contract DEAC02-76CH00016. 